\title{
Vertically transmitted dengue in a neonate born to a mother with asymptomatic dengue infection
}

\author{
*Nimesha Chamidani Gamhewage ${ }^{1}$, Medha Weerasekera ${ }^{1}$, M H M Nazmy ${ }^{1}$
}

Sri Lanka Journal of Child Health, 2019; 48(2): 168-169

DOI: http://dx.doi.org/10.4038/sljch.v48i2.8715

(Key words: Dengue fever, neonate)

\section{Introduction}

Historically, dengue was known to be a vector borne disease. There is a wide clinical spectrum of disease ranging from a non-specific acute febrile illness, dengue fever (DF) to dengue haemorrhagic fever (DHF) and dengue shock syndrome. Some can remain asymptomatic ${ }^{1}$. Vertical transmission of dengue infection is well known yet rare $^{2}$. In almost all the reported cases, the neonate was diagnosed after their mothers were identified as having dengue $^{2}$. We report a case of DF in a neonate, whose mother had asymptomatic infection, which was identified following the diagnosis of her newborn.

\section{Case report}

A three day old baby was admitted to the Special Care Baby Unit of the Sri Jayewardenepura General Hospital, Sri Lanka, due to fever of one day duration. Baby was born to a healthy primigravida. Birth weight was $3 \mathrm{~kg}$. There were no risk factors for sepsis. Examination revealed an icteric baby with $5 \%$ weight loss. Rest of the examination was unremarkable.
Septic screening was negative. Blood picture revealed no evidence of haemolysis and the reticulocyte count was $2 \%$. Presence of thrombocytopenia with reactive lymphocytes in a baby from a highly endemic area for DF prompted us to screen for possible dengue in the baby, even though mother denied having any febrile illness during the peripartum period. NS 1 antigen was positive in both mother and baby. Dengue antibodies were not detected in the baby on day 1 of fever but positive Ig M with negative Ig $\mathrm{G}$ was observed on day 7 of illness. Mother was positive for both on admission. His transaminases were normal and there was no evidence of leaking on serial sonograms.

Baby was monitored according to the National Guidelines on management of DF and DHF in children and adolescents formulated by the Ministry of Health, Sri Lanka in collaboration with the Sri Lanka College of Paediatricians ${ }^{1}$. He was managed with maintenance fluids according to the age. He received two platelet transfusions on $4^{\text {th }}$ and $5^{\text {th }}$ day of illness. Serial blood counts of the baby are shown in Table 1.

Table 1: Serial full blood counts

\begin{tabular}{|l|c|c|c|c|c|c|}
\hline \multicolumn{1}{|c|}{ Day of illness } & $\mathbf{2}^{\text {nd }}$ & $\mathbf{3}^{\text {rd }}$ & $\mathbf{4}^{\text {th }}$ & $\mathbf{5}^{\text {th }}$ & $\mathbf{6}^{\text {th }}$ & $\mathbf{7}^{\text {th }}$ \\
\hline White cells $/ \mu \mathrm{L}$ & 6,560 & 9,160 & 10,160 & 9,430 & 7,780 & 12,000 \\
\hline Neutrophils \% & 66 & 53 & 30 & 28 & 32 & 24 \\
\hline Lymphocytes \% & 17 & 30 & 47 & 50 & 54 & 55 \\
\hline Haemoglobin g/dl & 19.1 & 20 & 18.2 & 15.7 & 13.7 & 14.2 \\
\hline Platelets/ $\mu \mathrm{L}$ & 90,000 & 43,000 & 6,000 & 8,000 & 12,000 & 42,000 \\
\hline Haematocrit \% & 55 & 57.4 & 52.5 & 45.8 & 41.7 & 42 \\
\hline
\end{tabular}

Fever settled on day 2 of illness. Bleeding manifestations were limited to skin bleeding. Clinical recovery was observed on day six of illness,

\footnotetext{
${ }_{1}^{1}$ Sri Jayewardenepura General Hospital, Sri Lanka *Correspondence:nimeshagamhewage@gmail.com

$$
\text { KUSVURLFIGIRU D0000-0001-5129-4158 }
$$
}

(Received on 08 June 2017: Accepted after revision on 28 July 2017)

The authors declare that there are no conflicts of interest Personal funding was used for the project. followed by a steady rise in platelet levels from day 7 of illness.

\section{Discussion}

Transplacental dengue infection occurs, but protective antibodies also pass transplacentally and fetal effects may be minimal given sufficient immune response ${ }^{2}$. In near-term disease, severe fetal or neonatal illness and death may occur ${ }^{2}$. Such illness may also predispose the newborn to subsequent dengue haemorrhagic fever $(\mathrm{DHF})^{2,3}$. Further, cord antibody titres depend on maternal antibody titres and low birthweight babies have lower antibody transfer ratios ${ }^{4}$. Anti-dengue activity is detected in human milk and colostrum, which can protect the infant from the dengue infection ${ }^{3}$. 
Sirinavin et al had reviewed 17 neonates confirmed of having perinatal dengue infection. In this review all babies had presented with fever and thrombocytopenia, while 14 had hepatomegaly. Transient elevation of transaminases and erythematous rash had been observed in some babies. One neonate had intracerebral hemorrhage ${ }^{5}$.

Some newborns can remain afebrile ${ }^{6}$. Therefore cases of perinatal dengue could be missed in the absence of a maternal history of dengue fever, such as in a mother who had asymptomatic illness or undifferentiated fever. Incubation period of vertical infection has not been determined ${ }^{5}$. However, interval between the onset of fever in mothers and their neonates was found to be 5-13 days with a median of 7 days and the age at the onset of fever in the neonate had varied from 1 to 11 days after birth with an average of 4 days in a case series ${ }^{5}$. Whether the mother had primary or secondary infection was not associated with the age of onset of illness of their newborn ${ }^{5}$. As our patient presented with fever and thrombocytopenia on day 3 of life it is highly likely that he has got vertically transmitted infection rather than vector borne infection.

NS 1 antigen, dengue polymerase chain reaction (PCR) and antibodies are useful diagnostic tools in evaluating babies ${ }^{1}$. Interestingly, during infancy leucopenia is uncommon ${ }^{1}$. Therefore it could be difficult to differentiate DF from neonatal sepsis. There is no place for platelet transfusions in young children with dengue ${ }^{1}$. However neonatal guidelines suggest transfusing platelets in thrombocytopenic babies with platelet level less than 30,000/ microlitre, even in the absence of bleeding irrespective of aetiology ${ }^{7}$. Scarcity of clinical experience, management guidelines and unusual haematological parameters in neonates with dengue infection pose a challenge in diagnosing and management. It is prudent to exclude dengue infection in a thrombocytopenic neonate even in the absence of a maternal history.

\section{References}

1. Ministry of Health, Sri Lanka in collaboration with the Sri Lanka College of Paediatricians. National Guidelines on management of DF and DHF in children and adolescents: revised and expanded edition, December 2012. Available from: http://www.epid.gov.lk/web/images/pdf/P ublication/gmdfca12.pdf

2. Carroll ID, Toovey S, Van Gompel A. Dengue fever and pregnancy a review and comment. Travel Medicine and Infectious Disease 2007; 5:183-8.

https://doi.org/10.1016/j.tmaid.2006.11.00 2

PMid: 17448946

3. Jain A, Chaturvedi UC. Dengue in infants: an overview. FEMS Immunology \& Medical Microbiology 2010; 59(2): 11930 .

https://doi.org/10.1111/j.1574695X.2010. 00670.x

PMid: 20402771

4. Perret $\mathrm{C}$, Chanthavanich $\mathrm{P}$, Pengsaa K, et al. Dengue infection during pregnancy and transplacental antibody transfer in Thai mothers. Journal of Infection 2005; 51(4):287-93.

https://doi.org/10.1016/j.jinf.2004.10.003

PMid: 16291281

5. Sirinavin S, Nuntnarumit $P$, Supapannachart S, Boonkasidecha S,Techasaensiri C, Yoksarn S. Vertical dengue infection: case reports and review. Pediatric Infectious Disease Journal 2004; 23(11):1042-7.

https://doi.org/10.1097/01.inf.0000143644 $.95692 .0 \mathrm{e}$

PMid: 15545860

6. Pérez-Padilla J, Rosario-Casablanca R, Pérez-Cruz L, Rivera-Dipini C, Tomashek KM. Perinatal transmission of dengue virus in Puerto Rico: a case report. Open Journal of Obstetrics and Gynecology 2011; 1(3): 90-93. https://doi.org/10.4236/ojog.2011.13016

7. Rennie JM. Rennie and Roberton's Textbook of Neonatology. $5^{\text {th }}$ ed. Churchill Livingstone 2012. 